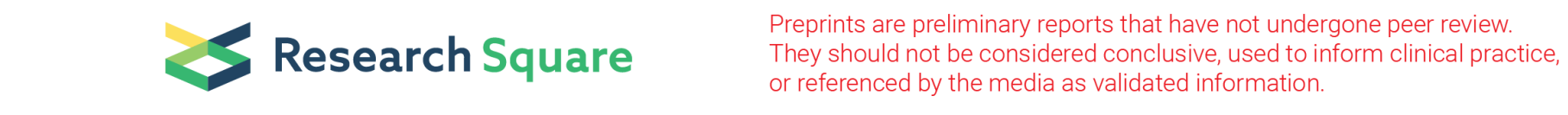

\title{
QTL-seq Analysis of Seed Size Trait in Grape Reveal New Insight on The Genetics of Seedlessness
}

\section{Li Wang}

Hebei Agricultural University

\section{Songlin Zhang}

Northwest Agriculture and Forestry University

\section{Chen Jiao}

Northwest Agriculture and Forestry University

Zhi Li

Northwest Agriculture and Forestry University

Chonghuai Liu

Chinese Academy of Agricultural Sciences \& Peking Union Medical College Hospital of Skin Diseases and Institute of Dermatology

Xiping Wang ( $\sim$ wangxiping@nwsuaf.edu.cn )

Northwest Agriculture and Forestry University https://orcid.org/0000-0002-8377-855X

\section{Research article}

Keywords: grape, genome, seedless, SNP

Posted Date: November 18th, 2019

DOI: https://doi.org/10.21203/rs.2.17413/v1

License: @ (1) This work is licensed under a Creative Commons Attribution 4.0 International License. Read Full License 


\section{Abstract}

Background Seedlessness in grape (Vitis vinifera) is an important commercial trait for both the fresh and drying markets. However, despite numerous studies, the mechanisms and key genes regulating grape seedlessness are mostly unknown.

Results In this study, we sequenced the genomes of the V. vinifera seeded cultivar 'Red Globe', the seedless cultivar 'Centennial', as well as the derived hybrids. Nonsynonymous SNPs were identified and analyzed with respect to published transcriptome data. All the DEGs containing nonsynonymous SNPs were further analyzed in terms of expression patterns, Gene Ontology and pathway enrichment. A potential QTL region associated with seed size was characterized based on SNP indices for both seedless and seeded progeny. Expression analysis of candidate genes during ovule development in multiple seeded and seedless grape cultivars further indicates their potential function in grape seed development.

Conclusion In summary, DEGs containing nonsynonymous SNPs were mainly protein kinase, transcription factors, cytochrome P450 and other factors related to seed development, which were mainly involved in biological processes like hormone balance, seed coat and endosperm development, reproductive organ development, oxidation and reduction, senescence and cell death. Based on SNP-index and expression pattern analysis, three genes were further identified as potential seedlessness-related genes. Overall the data cast light on the differences of seed development between seeded and sedless progeny in perspective of both functional variants and expression pattern,which provides valuable candidates for future functional study.

\section{Background}

Seedlessness in grape is an important focus of research, since seedless fruit are preferred for fresh consumption and processing. Based on distinctions related to pollination and fruit development, seedlessness in grape can be classified as parthenocarpy, where fertilization is absent, or stenospermocarpy, characterized by normal fertilization with subsequent abortion [1,2]. Most commercial seedless grape cultivars are stenospermocarpic, and since this trait is heritable which can pass hereditary feature to the next generation and usually used as parent in breeding, such as the typical seedless cultivar 'Thompson Seedless'.

Over the past several decades, significant progress has been made in characterizing the genetic mechanisms underlying grape seedlessness. On one hand, Research has been focused on mapping and identification of genetic loci influencing this trait, aiming to develop molecular markers to increase the speed and efficiency of seedless grape breeding. Seedlessness has been reported to be a quantitative trait mapping to at least seven loci [3-6], comprising one major-effect locus and several complementary recessive loci [4]. One Random Amplified Polymorphic DNA (RAPD) marker, UBC-269500, was found to be linked to a major seedlessness locus using bulked segregant analysis (BSA) [7]. Two RAPD markers were obtained and tightly linked to the dominant / gene, and the closest marker was further developed into a SCAR (Sequence Characterized Amplified Region) marker, designated SCC8 [8,9]. In addition, another SCAR marker, SCF27, was identified [10]. Grape seedlessness was further studied using QTL (Quantitative Trait Locus) analyses, and a major QTL VMC7F2 underlying seed fresh weight was developed [3]. On the other hand, an assortment of candidate genes associated with grape seed development has also been identified. A gene named Chloroplast Chaperonin 21 (ch-Cpn21) was found to be differentially expressed in the inflorescence of seedless and seeded grapes, and silencing of this gene promoted seed abortion in tobacco and tomato fruits [11].

In addition, an EF-hand calcium-binding protein designated VvCBP1 was reported to be related to seedlessness, and silencing of this gene in tomato reduced seed number in fruit [12]. And $V V A G L 11$, an ortholog of the AGAMOUStike 11 gene of Arabidopsis, was identified to be the major function candidate gene for seedlessness [13]. Moreover, the grape berry-specific basic helix-loop-helix transcription factor VvCEB1 was reported to affect cell size [14]. In addition, some MADS-box genes, which show strong homology to an Arabidopsis ovule identity gene, were found to be differentially expressed during ovule development in multiple seeded and seedless grape cultivars, indicating a potential role in ovule development [15]. Moreover, nowdays omics analysis has cast light on mechanism related to grape seedlessness, evidence showed that parthenocarpy in the grapevine seedless somatic variant Corinto bianco was caused by the absence of a mature macrogametophyte which was 
probably due to meiosis arrest [16]. A transcriptome analysis of ovule development in grape hybrids was used to develop a network map of possible mechanisms influencing seed size [17]. Recently, the major origin of seedless grapes was found to be associated with a missense mutation in the MADS-box gene VviAGL 11 with two F1 mapping populations [18]. In general, despite all the progress made in molecular biology underlying grape seedlessness, the grape ovule identity gene and corresponding regulation mechanism was still not clear enough.

Recently, decreasing sequencing costs and increasing quality of output has facilitated the generation of large amounts of sequence data. Whole-genome resequencing combined with QTL analyses (QTL-seq) has enabled rapid identification of the genomic regions underlying specific traits [19]. For example, QTL-seq in rice successfully identified QTLs associated with seedling vigor and resistance to the fungal rice blast disease [20]. Likewise, sequencing of bulked-segregant populations has contributed to a number of scientific studies. For example, a study combining transcriptome sequencing (RNA-seq) with BSA developed single nucleotide polymorphisms (SNPs) in polyploidy species [21], whereas another identified gene associated with disease resistance against enteric septicemia in catfish [22]. In addition, deep genome sequencing of bulked-segregant populations identified a MIXTAlike R2R3 MYB gene influencing epidermal cell development and carotenoid pigmentation in Mimulus lewisii [23].

In this study, we exploited whole genome sequencing to identify genomic regions co-segregating with the seedless trait in bulked populations derived from a cross between a seedless and seeded cultivar. Sequence variants likely to affect gene function were identified and analyzed with respect to previously published ovule transcriptome data [17] in order to identify variants and genes potentially affecting seed size. The whole experiment design was shown in Figure 1. The results of our study will enhance the knowledge of the fundamental mechanisms of grape seed development and have potential to accelerate breeding efforts for seedless cultivars.

\section{Results}

\section{Data Filtering and High Quality Clean Reads Mapped with Reference Genome}

The base composition and quality value before and after filtering is shown in Additional file 1: Figure S1, Additional file 2, Table S1 and Additional file 3: Table S2. The Q20 value of all samples was $>98.9 \%$ and the Q30 value $96 \%$. The alignment rates to the reference genome for each sample, including the parental cultivars 'Red Globe' (R.G) and 'Centennial seedless' (C), and pooled seeded (S) and seedless (SL) progeny, were >95\% (Table 1).

\section{Identification and Classification of Single Nucleotide Polymorphisms (SNPs) and Small Indels Based on Genome Re-sequencing}

To catalog genetic diversity in grapevine and its potential influence on gene function in the context of ovule development, we carried out whole genome re-sequencing of the parental cultivars 'Red Globe' and 'Centennial seedless', as well as their pooled seeded and seedless progeny. A total of 6,379,614 SNPs and 745,433 small indels were identified among these four samples. All of the identified variants were indexed based on their genomic position (Figure 2a). Most variants were found in the intergenic regions, followed by intronic, upstream, downstream and exonic regions. The least number of variants were found in the 5' UTR regions. A total of 222,652 variants were located within exons. We classified these further based on their potential effects on gene function (Figure $2 b$ ). We focused our attention on those variants predicted to cause amino acid changes in protein coding genes (frameshift, substitution, premature termination, and loss of termination). Four kinds of transition and eight kinds of transversions were identified, with $\mathrm{C}$ to $\mathrm{G}$ transversion and $\mathrm{G}$ to $\mathrm{A}$ transition the most common. The ratio of transition to transversion was 0.48 , which is close to the ratio of 0.5 in the ideal condition.

\section{Gene Ontology (GO) and Pathway Analysis of Identified DEGs Containing Functional Variants}


To identify functional variants most closely related to seedlessness, we analyzed these results in the context of transcriptome data using the same progeny as plant materials, aiming to further identify functional variations which may alter the expression of the gene. Functional variations were identified from genome data and the number of corresponding associated genes are shown in Table 2. In addition, a relative comprehensive statistical analysis was conducted in combination of both genome and transcriptome data, and the number of functional variants containing genes identified as DEGs at least at one stage and at all three developmental stages were counted based on function classification of variants (Table 2). With respect

to ovule development comparing the seeded and seedless progeny at Stage 1, Stage 2 and Stage 3, a total of 2,425, 2,988 and 2,328 DEGs containing functional variants were identified, respectively (Additional file 4囚Table S3). At each ovule developmental stage, the number of up-regulated DEGs (seedless progeny/seeded progeny) were found to be higher than down-regulated ones. Moreover, the number of DEGs containing functional variations were found to be highest at Stage 2, irrespective of whether the gene was up- or down-regulated.

To explore the biological processes and pathways associated with DEGs containing functional variations, we performed a GO and pathway analysis of the DEGs containing functional variants at three developmental stages. In general, results of both enriched GO and pathway were basically consistent and focused on aspects involved in seed development. A total of $162 \mathrm{GO}$ terms were found to be significantly enriched at all three developmental stages (Figure 3a). Those GO terms associated with up-regulated DEGs were mainly involved in biological processes like plant defense, regulation of reproductive development, regulation of hormone balance, seed coat development, endosperm and seed development, and cell death (Figure 3b). On the other hand, GO terms associated with down-regulated DEGs were mainly related to 'lignin biosynthetic process', 'secondary metabolic process', 'oxidation reduction' and 'iron ion transport' (Figure 3b). A total of 124 pathways were found to be enriched at all three ovule developmental stages (Figure 4a), and these enriched pathways were mainly related to regulation of hormone balance ('cytokinins degradation', 'cis-zeatin biosynthesis', 'jasmonic acid biosynthesis' and 'ethylene biosynthesis from methionine'), seed coat development ( 'cellulose biosynthesis' and 'suberin biosynthesis'), secondary metabolic biosynthesis ('flavonoid biosynthesis') and oxidation-reduction ('glutathione-mediated detoxification') (Figure 4b).

\section{Functional and Expression Analysis of DEGs Containing Functional Variants}

We focused further attention on functional variant-containing genes that were differentially expressed in the developing ovules, between seeded and seedless cultivars, at all three ovule developmental stages (Table 2). We estimated gene function based on their annotation, and focused on genes encoding potential disease resistance protein, protein kinase, transcription factor, cytochrome P450 and other factors affecting seed development.

Functional variants within genes encoding protein kinases were found to be nonsynonymous SNP, frameshift deletion, frameshift insertion, stopgain and stopless (Figure 5a). The expression patterns of these DEGs were almost similar at all three ovule developmental stages, i.e., mainly up-regulated in seedless progeny compared with seeded ones. In addition, disease resistance proteins are important during plant defense responses. We found that many functional variant-containing DEGs encoded disease resistance proteins; these variants comprised nonsynonymous SNP, frameshift deletion, frameshift insertion and stopless (Figure 5b).The expression pattern of all the disease resistance protein associated DEGs at the three development stages was nearly the same, irrespective of the functional effects of the variants, with most DEGs up-regulated in the ovules of seedless progeny compared with seeded progeny. Many DEGs containing functional variants (nonsynonymous SNP, frameshift deletion, frameshift insertion, stopgain and stopless) were identified within cytochrome P450-like genes, and most of these DEGs were up-regulated in seedless progeny compared to seeded ones at all three developmental stages. It is noteworthy that, irrespective of whether the gene was up- or down-regulated, the expression pattern of these DEGs showed no differences among all three developmental stages.

Moreover, many DEGs identified as transcription factors (TF) were found to contain functional variants including nonsynonymous SNP, frameshift deletion, stopgain and stopless (Figure 6). These TFs were classified into 15 families, among which MYB and BHLH were the top two families with the most number of DEGs containing function variants. Expression of DEGs associated with 10 TF families (WRKY, BHLH, SBP, AP2, Myb, HB, TCP, HSF, CCAAT and GRAS) were found to be up- 
regulated at all three ovule developmental stages in seedless progeny compared to seeded progeny. In contrast, an assortment of genes were down-regulated at all three ovule developmental stages in seedless progeny compared to seeded ones; these included one NAC, two MADS-box, one GATA, one bZIP, and one ERF family gene.

DEGs containing functional variants were also classified into 12 other functions associated with seed development, including heavy-metal-associated protein, cellulose-related protein, ankyrin repeat-containing protein, senescence-associated protein, hormone-related protein, calmodulin, methyltransferase, cell cycle, $A B C$ transporter protein, thaumatin, aspartic proteinase and flavonoid synthase. Expression pattern of these DEGs was shown in Figure 7. Two kinds of functional variants were identified in heavy-metal-associated protein (nonsynonymous SNP and frameshift insertion) and methyltransferase (nonsynonymous SNP and frameshift deletion), while only one kind of function variant (nonsynonymous SNP) was identified in others. Expression of DEGs encoding cellulose-related protein, ankyrin repeat-containing protein, senescence-associated protein, calmodulin and cell cycle were up-regulated at all three ovule developmental stages in seedless progeny compared to seeded ones $\square$ while expression of DEGs encoding several of the other functions were down-regulated. Except for one DEG encoding methyltransferase which was found to be down-regulated at Stage 1 but up-regulated at Stages 2 and 3, all other DEGs showed consistency in expression pattern among all three ovule developmental stages.

\section{Identification of seedless candidate genes based on SNP-index analysis of two extreme pools}

For each progeny bulk, the frequency of each SNP variant (SNP-index) was calculated, and a delta SNP-index was determined (Additional file 5: Figure S2). A number of 3 peaks on chromosomes 11, 13 and 17, as well as 3 valleys on chromosomes 6, 7 and 8 under the threshold for delta-SNP index were identified. A total of 7,923 SNPs were identified within the peak regions, while 360 SNPs were identified in the valley regions. A total of 13 nonsynonymous SNPs were identified in the valley regions, including 1 variant on Chromosome 6 associated with 1 gene, 6 variants on Chromosome 7 associated with 4 genes, and 6 variants on Chromosome 8 associated with 4 genes (Additional file 6囚Table S4). In the peak regions, a total of 38 functional variants were identified (Additional file 7囚Table S5), among which 35 variants (34 nonsynonymous SNP and 1 stopgain) were located on Chromosome 13 and were associated with 18 genes. The other 3 nonsynonymous SNP were found on Chromosome 17 and associated with 2 genes.

All in all, a total of 33 genes were identified as potential preliminary candidates based on the SNP-index analysis, among which some genes were found to contain more than one functional variant. We examined the expression pattern of these genes during ovule development in previously generated datasets derived from the same progeny. It is noteworthy that the arginine-197-to-leucine substitution on Chromosome 18 in VviAGL 11 [18] was also identified in our results, but as this SNP was not performed good enough in our SNP-index analysis compared to other selected genes. And consistent with the expression pattern reported, VViAGL 11 was not identified as significant DEGs according to transcriptome analysis. In consideration of all this, we did not carry further research on this gene. And nine candidate genes were further yield by the standard of being DEGs at at least one ovule developmental stage of 3 and corresponding information can be found in Table 3 and Additional file 8: Figure S3. One of these nine genes, G2,was down-regulated at all three ovule developmental stages in seedless progeny compared to seeded ones. Expression of the other eight candidate genes was up-regulated at at least one ovule developmental stage in seedless progeny compared to the seeded ones.

\section{Expression analysis of candidate genes related to seedlessness}

To further investigate a potential role for these nine candidate genes in ovule development and seedlessness and explore whether the different expression pattern between seeded and seedless progeny was widely applied, we analyzed their expression in different grapevine tissues (Figure 8) and in ovules at different development stages (Figure 9) from seeded and seedless cultivars. All candidate genes were expressed in reproductive tissues (flowers, tendrils and fruits). Both the $G 1$ and G2 genes show strong expression in reproductive tissues, compared with nutritional tissues, whereas the G8 gene was

Page 5/22 
expressed more strongly in nutritional tissues (Figure 8). The expression pattern of $G 1, G 8$ and $G 9$ genes were similar between seeded and seedless varieties, while $G 5, G 6$ and $G 7$ genes were differentially expressed. For example, $G 5$ expression was relatively high in fruit of 'Red Globe' and leaves of 'Thompson Seedless', while $G 6$ and $G 7$ were relatively highly expressed in the root of 'Thompson Seedless'.

As nine candidate genes showed different expression pattern during ovule development of seeded and seedless progeny, to further test whether this different expression pattern also exist in multiple grape cultivars, and to evaluate whether the observed cultivar-associated difference in expression pattern might be related to seedlessness, we analyzed expression of the nine candidate genes in two seeded ('Kyoho' and 'Red Globe') and two seedless cultivars ('Thompson Seedless' and 'Flame Seedless') (Figure 9). The expression pattern of most of the candidate genes was consistent with the transcriptome data, except that some genes showed differences at specific stages, likely related to cultivar difference (Figure 9). Six of the candidate genes exhibited a consistent expression pattern at all three ovule developmental stages between cultivars: four genes ( $G 4, G 7, G 8$ and $G 9$ ) showed higher expression in seedless cultivars compared to seeded ones, while two genes ( $G 2$ and G5) showed the opposite. In transcriptome data (Table 3), expression of G5 gene was first up-regulated at stage 1 then downregulated at stage 2 and 3 (seedless progeny/seeded progeny), while G5 genewas down-regulated (seedless cultivars/seeded cultivars) at all three developmental stages between multiple cultivars. Despite $G 5$ gene showing some difference, the expression pattern of the remaining five candidate genes was consistent with transcriptome data, which indicates the widely applicability of different expression during ovule development of seeded and seeded cultivars and underscored the utility of these candidate genes underlying seed phenotype differences.

\section{Discussion}

In this study, we combined whole genome sequencing with bulk segregation analysis of seeded and seedless progeny derived from the seeded maternal parent 'Red Globe' and the seedless paternal parent 'Centennial seedless' to identify genes with potential function in ovule/seed development. These genes were further assessed in relation to published ovule transcriptome data using the same plant progeny materials. SNP-index analysis combined with expression profiles resulted in the identification of potential candidate genes containing function variants. This adds to our knowledge of grape seedlessness and may contribute to seedless grape breeding in the future.

\section{Overall Differences of DEGs Containing Functional Variants between Seeded and Seedless Grape Progeny}

DEGs containing functional variants were identified by combining data from genome sequencing and RNA-seq using the same grape progeny. Further functional analysis showed that overall differences of these DEGs between seeded and seedless grape progeny were mainly enriched in important biological processes and pathways involved in seed development, including reproductive organ development, hormone balance regulation, seed coat development, endosperm development, senescence and cell death (Figure 3 and 4). In addition, many DEGs containing functional variants were identified as protein kinases, TFs, TRs, cytochrome P450 and genes related to seed development. Protein kinases are key factors in plant biological processes such as energy metabolism and signal transduction. Protein kinases participate in hormonal signaling cascades in plants, and there have been in increasing reports of protein kinases regulating plant reproductive tissue development. In Petunia, a Pollen-Expressed Receptor-like Kinase gene (PRK1) was found to play a role in signal transduction events during pollen development and pollination [24]. In Arabidopsis thaliana, a receptor-like protein kinase, HAESA, was reported to control floral organ abscission [25], and GSK3/Shaggy like kinase AtSK3-2 was found to play an important role in the control of cell elongation during flower development [26]. Based on the fact that plant protein kinases participate in the regulation of reproductive tissue development, we infer that DEGs containing functional variants, identified as protein kinases, may be related to phenotypic differences of ovules between seeded and seedless progeny.

Other factors influencing seed development include cytochrome P450s, ankyrin repeat-containing proteins, calmodulins, ABC transporter proteins and so on. In plants, ankyrin repeat-containing proteins mediate protein-protein interactions to regulate 
signal transduction related to development and plant defense response. In lily, an ankyrin repeat-containing protein characterized as a ubiquitin ligase was found to be required for pollen germination and pollen tube growth [27]. Moreover, plant calcium ions can influence pollen tube growth, and the $V_{V} C B P 1$ gene encoding an EF-hand calcium-binding protein was reported to be associated with fruit seedlessness of grapevine [12]. Other factors such as $A B C$ transporter proteins have also been reported to influence plant reproductive tissue development. For example, an ATP-binding cassette transporter from rice, OsABCG15, was found to be required for anther development and pollen fertility [28]. Because the DEGs containing functional variants identified in this study represented these various functional classes, we propose that they may participate in biological processes and pathways involved in seed development and influence the seedless trait.

\section{Some DEGs Containing Functional Variants were Identified as Candidates associated with Grape Seed Size by QTL-Seq Analysis}

Based on the potential function of candidate genes, we further carried out gene expression analysis during ovule development among multiple cultivars. The results, in combination with both gene annotation and previous related functional studies, suggest that three genes in particular, G2, G4 and G8, may be determinants of grape seedlessness.

In Arabidopsis, the AUXIN RESPONSE FACTOR 2 (ARF2) gene links auxin signalling, cell division, and the size of seeds and other organs [29]. As auxin regulators, ARFs can interact with AUX/IAA proteins to repress the content of auxin and regulate corresponding subsequent biological processes. The grapevine $V v C E B 1$ gene, which was reported to influence cell size, functions by influencing auxin metabolism and cell signaling [14]. Prior to fertilization, ovary growth is blocked by the repressive action of AUX/IAA-ARF complexes on auxin-responsive genes. With pollination and fertilization, the level of auxin in ovules or ovary increases and derepresses ovary growth, which is necessary for fruit initiation [30]. ARFs function to guarantee the corresponding biological process proceeds in an orderly manner to ensure seed viability. For example, in Arabidopsis and tomato, mutation of ARF8 and SIARF7 both lead to seedlessness [30,31]. In our results, the G2 gene, identified as encoding a putative auxin response factor, was differently expressed in ovules between seeded and seedless progeny, and this expression pattern was also consistent in ovules of multiple other cultivars. In view of the reported function of ARFs, this implies that $G 2$ may be a key gene related to seedlessness.

In addition, the $G 4$ was annotated as a putative cytochrome P450 monooxygenase. This class of gene is known to participate in the balance regulation of GA and auxin. In rice, ELONGATED UPPERMOST INTERNODE (EUI) encodes a cytochrome P450 monooxygenase that epoxidizes gibberellins to reduce their concentration [32]. The Arabidopsis cytochrome P450 monooxygenasegene $71 A 13$ and YUCCA were reported to be involved in auxin synthesis [33,34]. These studies indicate that the influence of monooxygenases on plant growth and development is via regulating GA and auxin content. In the seedless vs. seeded progeny populations used for transcriptional profiling, the content of both GA and auxin was significantly higher in seedless progeny compared to seeded ones during ovule development [17]. Also, overexpression of a gene encoding a cytochrome P450, CYP78A9, caused large and seedless Arabidopsis fruit [35]. In view of these reports, we speculate that the content of GA and auxin is critical for seed formation, and that G4 is a key gene associated with seedlessness. Moreover, the G8 gene was annotated as a putative Aluminum-activated Malate Transporter (ALMT). Most studies about ALMT demonstrated its important function in malic acid transport [36]. In apple, a natural mutation leading to truncation of the ALMT protein at the Ma locus was reported to be associated with low fruit acidity [37], but to our knowledge, there are no reports of ALMT related to seed development. Our results show that $G 8$ is found within the genomic interval identified by QTLseq analysis as influencing seedlessness, that the expression of the $G 8$ gene is significantly different during ovule development in multiple seedless vs seeded cultivars. These results implicate G8, and ALMT activity as key factors influencing seedlessness, and thus $G 8$ is an excellent candidate for further functional studies.

\section{Conclusions}

In summary, genome sequencing analysis in combination with transcriptome data was conducted using grape progeny derived from the seeded maternal parent 'Red Globe' and the seedless paternal parent 'Centennial seedless'. All DEGs

Page $7 / 22$ 
containing functional variants were identified, so as relate biological processes and pathways. Based on SNP index and expression analysis, a total of three genes in the QTL region were identified as candidates related to grape seedlessness, which provides valuable candidates for further functional research and adds our knowledge for seedless grape breeding.

\section{Methods}

\section{Plant Material}

A total of 114 F1 individuals were obtained from a cross between the seeded maternal parent 'Red Globe' (V. vinifera) and the seedless paternal parent 'Centennial seedless' (V. vinifera) in 2009. All seedling plants were developed and maintained at the Zhengzhou Fruit Institute, Zhengzhou, China ( $\left.113^{\circ} 42^{\prime} \mathrm{N} 34^{\circ} 43^{\prime} \mathrm{E}\right)$, and seed phenotypes were evaluated for three years. A total of 65 progeny with stable seed phenotype were obtained, including 31 seedless and 34 seeded. Of these, 19 seeded and 19 seedless individuals were randomly selected as experimental materials for genome sequencing. All the plant materials used and collected in this work comply with China's guidelines and legislation.

\section{Sample Collection and Genomic DNA Library Construction, Sequencing and Data Analysis}

For expression analysis, plant structures (young roots, stems, leaves, tendrils, flowers at the fully opening stage, and fruit at 30 days post-anthesis) were collected from 'Red Globe' and 'Thompson Seedless' seedlings. Ovules were dissected from two seeded ('Kyoho' and 'Red Globe') and two seedless ('Thompson Seedless' and 'Flame Seedless') cultivars at different developmental stages and weighed, as described previously [15]. All plants were identified and maintained in the grape germplasm resource orchard of Northwest Agriculture \& Forestry University, Yangling, China $\left(34^{\circ} 20^{\prime} \mathrm{N} 108^{\circ} 24^{\prime} \mathrm{E}\right)$. Three landmark ovule developmental stages were defined based on ovule weight change (initial stage, stage with the highest weight, and stage with the lowest weight) as done previously [17]. Samples were immediately frozen in liquid nitrogen and stored at $-80^{\circ} \mathrm{C}$ for subsequent gene expression analysis. And the plant materials used and collected in this work comply with China's guidelines andlegislation.

For genomic sequencing, young leaves from 19 seedless or 19 seeded progeny were collected and pooled. DNA was extracted from each pooled leaf sample, using equivalent mass of sample from each pool. Sequencing libraries for the bulk and the parents were prepared using the Genomic DNA Sample Prep kit (Illumina, San Diego, CA) according to the manufacturer's protocol. The libraries were sequenced using an Illumina HiSeq 2500 system for 151 cycles, operating in the paired-end mode. The resulting raw Illumina reads were processed to remove duplicated read pairs (defined as those having identical bases in the first $100 \mathrm{bp}$ of both left and right reads). Illumina adaptor sequences and low quality sequences were trimmed from the reads using Trimmomatic [38]. Read pairs with read $<40$ bp were excluded from further analysis. Resulting paired-end reads were mapped to a grape reference genome (PN40024; 12X) [39] using BWA [40]. Only reads that mapped uniquely (i.e. having one single best hit) to the genome were used for SNP calling. SNPs and small indels ( $1-5 \mathrm{bp})$ were identified based on the alignment information in the pileup format generated by SAMtools [41].

DEGs containing nonsynonymous SNPs were identified using published transcriptome data (NCBI SRA accession SRP081137), previously generated from the same progeny populations [17]. GO and pathway enrichment analysis were performed using Plant MetGenMAP [42]. The raw sequencing data has been deposited in NBCI SRA under the accession number SRP174903.

\section{QTL Analysis of Seed Size based on SNP Index}

A SNP index was calculated for each SNP, and sliding window analysis was applied with a $2 \mathrm{Mb}$ window size and $100 \mathrm{~kb}$ increment. The average SNP index within the window was used for sliding window plot drawing, and SNPs with a number less than 10 were excluded. To filter spurious SNPs called due to sequencing and/or alignment errors, SNP positions with SNP-

Page $8 / 22$ 
index of $<0.3$ and read depth $<7$ were also excluded. $A \triangle$ (SNP-index), derived from SNP-index for each bulked pool, was further calculated [20]. The QTL region associated with seed size was then identified based on an arbitrary threshold of the top $0.5 \%$ of $\triangle$ (SNP-index) [43].

\section{Semi-quantitative RT-PCR}

The grapevine Actin 1 gene (GenBank Accession number AY680701) which was amplified with the primers $F$ ( $5^{\prime}$ -

GATTCTGGTGATGGTGTGAGT-3') and R (5'-GACAATTTCCCGTTCAGCAGT-3') and EF1-a gene (GenBank Accession number EC931777) amplified with the primers $F$ (5'-AGGAGGCAGCCAACTTCACC-3') and R (5'-CAAACCCTGCATCACCATTC-3') were used as reference genes for semi-quantitative RT-PCR. Gene-specific primers can be found in Additional file 9: Table S6. PCR was carried out in a $20 \mu \mathrm{l}$ reaction volume containing $1 \mu \mathrm{l}$ CDNA template, $1.6 \mu$ l gene-specific primers $(1.0 \mu \mathrm{M}), 9.8 \mu \mathrm{l} \mathrm{PCR}$ Master Mix (Tiangen Biotech Co. Ltd., Beijing, China) and $7.6 \mu \mathrm{l}$ sterile distilled water. Amplification parameters were $94^{\circ} \mathrm{C}$ for $2 \mathrm{~min}, 25-38$ cycles of $94^{\circ} \mathrm{C}$ for $30 \mathrm{~s}$, and $55-62^{\circ} \mathrm{C}$ for $30 \mathrm{~s}$ and $72^{\circ} \mathrm{C}$ for $30 \mathrm{~s}$, with a final extension cycle of $72^{\circ} \mathrm{C}$ for $2 \mathrm{~min}$. PCR was conducted for three biological replicates for each assay. For each replicate, $5 \mu \mathrm{l}$ of the PCR products were visualized on a $1.5 \%(\mathrm{w} / \mathrm{v})$ agarose gel stained with ethidium bromide and photographed under UV light [15].

\section{Quantitative RT-PCR Analysis}

Quantitative real-time RT-PCR was carried out using a Bio-Rad iQ5 thermocycler (Bio-Rad, Hercules, CA, USA). For each sample, $1 \mu \mathrm{g}$ of total RNA was converted into cDNA using PrimeScript ${ }^{\text {TM }}$ RTase and an oligo dT primer (TaKaRa Biotechnology, Dalian, China) and was subsequently diluted 6-fold with sterile water. Each reaction was carried out in triplicate with a reaction volume of $20 \mu \mathrm{l}$ containing $0.8 \mu \mathrm{l}$ each primer $(1.0 \mu \mathrm{M}), 1.0 \mu \mathrm{l}$ of cDNA, $10 \mu \mathrm{l}$ of SYBR green (TaKaRa Bio Inc.), and $7.4 \mu \mathrm{l}$ sterile distilled water. The amplification parameters were $95^{\circ} \mathrm{C}$ for $30 \mathrm{~s}$, followed by 40 cycles of $95^{\circ} \mathrm{C}$ for $5 \mathrm{~s}$ and $60^{\circ} \mathrm{C}$ for 30 s. Melting-curve analyses were performed with initial incubation at $95^{\circ} \mathrm{C}$ for $15 \mathrm{~s}$ and then a constant increase from $60^{\circ} \mathrm{C}$ to $95^{\circ} \mathrm{C}$. ACTIN1 was used as a reference gene. Relative expression levels were analyzed using the IQ5 software and the normalized-expression method [44].

\section{List Of Abbreviations}

Abscisic acid, ABA; AGAMOUS, AG; Aluminum-activated Malate Transporter, ALMT; AUXIN RESPONSE FACTOR 2, ARF2; Bulked Segregant Analysis, BSA; Chloroplast Chaperonin 21, ch-Cpn21; ELONGATED UPPERMOST INTERNODE, EUl; Gene Ontology, GO; Pollen-Expressed Receptor-like Kinase, PRK; Quantitative Trait Locus, QTL;Sequence Characterized Amplified Region, SCAR; Single Nucleotide Polymorphism, SNP; S Receptor Kinase, SRK; transcription factor, TF; transcription regulators, TR

\section{Declarations}

\section{Ethics approval and consent to participate}

Not applicable.

\section{Consent for publication}

Not applicable.

\section{Availability of data and material}

The raw sequencing data has been deposited in NBCI SRA under the accession number SRP174903. The datasets supporting the conclusions of this article are included within the article and its additional files. 


\section{Competing interests}

The authors declare that they have no competing interests.

\section{Funding}

This work was supported by the Joint Funds of the National Natural Science Foundation of China (U1603234), the Program for Innovative Research Team of Grape Germplasm Resources and Breeding (2013KCT-25), Chinese Universities Scientific Fund (Z109021571 and 2452019170) and the Strat-up Funds of Agricultural University of Hebei to Li Wang (3002013). These funding bodies had no role in the design of this study, collection, analysis, and interpretation of data or in writing the manuscript.

\section{Authors' contributions}

X. W. and L. W. designed the research; X. W. supervised the experiments; L. W. performed most of the experiments; S. Z. and Z. L. provided technical assistance; L. W. and C. J. analyzed the data; C. L. provided the experimental materials; L. W. and X. W. wrote the article with contributions of all the authors. All authors read and approved the final manuscript.

\section{Acknowledgements}

We thank Prof. Steve van Nocker from Michigan State University for editing this manuscript. The authors thank all editors and reviewers for their comments on this manuscript.

\section{References}

1. Ledbetter CA, Ramming DW. Seedlessness in Grapes. In: Horticultural Reviews. John Wiley \& Sons, Inc.; 1989; $159-184$.

2. Ledbetter CA, Burgos L. Inheritance of Stenospermocarpic Seedlessness in Vitis vinifera L. J HERED. 1994; 85(2):157-160.

3. Cabezas JA, Cervera MT, Ruiz-García L, Carreño J, Martínez-Zapater JM. A genetic analysis of seed and berry weight in grapevine. Genome. 2006; 49(12):1572-1585.

4. Doligez A, Bouquet A, Danglot Y, Lahogue F, Riaz S, Meredith C, et al. Genetic mapping of grapevine (Vitis vinifera L.) applied to the detection of QTLs for seedlessness and berry weight. THEOR APPL GENET. 2002; 105 (5): $780-795$.

5. Striem M, Spiegel-Roy P, Baron I, Sahar N. The degrees of development of the seed-coat and the endosperm as separate subtraits ofstenospermocarpic seedlessness in grapesI. VITIS. 1992; 31: 149-155.

6. Striem MJ, Ben-Hayyim G, Spiegel-Roy P. Identifying molecular genetic markers associated with seedlessness in grape. J AM SOC HORTIC SCI. 1996;121(5): 758-763.

7. Wang Y, Lamikanra O. Analysis of sequencing the RAPD marker linked to seedless genes in grapes. Acta Universitatis Agriculturalis Boreali-occidentalis. 1996; 25(4):1-5.

8. Lahogue F, This P, Bouquet A. Identification of a codominant scar marker linked to the seedlessness character in grapevine. THEOR APPL GENET. 1998; 97(5):950-959.

9. Adam-Blondon AF, Lahogue F, Bouquet A, Boursiquot JM, This P. Usefulness of two SCAR markers for marker-assisted selection of seedless grapevine cultivars. VITIS. 2001; 40(3):147-156.

10. Mejia N, Hinrichsen P. A new, highly assertive SCAR marker potentially useful to assist selection for seedlessness in table grape breeding. In: VIII International Conference on Grape Genetics and Breeding 603: 2002; 2002: 559-564.

11. Hanania U, Velcheva M, Or E, Flaishman M, Sahar N, Perl A: Silencing of chaperonin 21, that was differentially expressed in inflorescence of seedless and seeded grapes, promoted seed abortion in tobacco and tomato fruits. TRANSGENIC RES. 2007; 16(4):515-525. 
12. Wang S, Yu Y, Zhang C, Xu W, Wang Y. Molecular cloning and characterization of a novel gene encoding an EF-hand calcium-binding protein related to fruit seedlessness of grapevine. MSCI HORTIC-AMSTERDAM. 2011; 130(4):708-714.

13. Mejia N, Soto B, Guerrero M, Casanueva X, Houel C, Miccono Mde L, et al. Molecular, genetic and transcriptional evidence for a role of $V V A G L 11$ in stenospermocarpic seedlessness in grapevine. BMC Plant Biol. 2011; 11: 57.

14. Nicolas $P$, Lecourieux D, Gomes E, Delrot S, Lecourieux F. The grape berry-specific basic helix-loop-helix transcription factor VvCEB1 affects cell size. J Exp Bot. 2013; 64(4):991-1003.

15. Wang L, Yin X, Cheng C, Wang H, Guo R, Xu X, et al. Evolutionary and expression analysis of a MADS-box gene superfamily involved in ovule development of seeded and seedless grapevines. Mol Genet Genomics. 2015; 290(3):825846.

16. Royo C, Carbonell-Bejerano P, Torres-Perez R, Nebish A, Martinez O, Rey M, et al. Developmental, transcriptome, and genetic alterations associated with parthenocarpy in the grapevine seedless somatic variant Corinto bianco. $\mathrm{J}$ Exp Bot. 2015.

17. Wang L, Hu X, Jiao C, Li Z, Fei Z, Yan X, et al. Transcriptome analyses of seed development in grape hybrids reveals a possible mechanism influencing seed size. BMC genomics. 2016; 17(1):898.

18. Royo C, Torres-Pérez R, Mauri N, Diestro N, Cabezas JA, Marchal C, et al. The Major Origin of Seedless Grapes Is Associated with a Missense Mutation in the MADS-Box Gene VviAGL11. PLANT PHYSIOL. 2018; 177(3):1234-1253.

19. Mackay I, Caligari P. Efficiencies of F and Backcross Generations for Bulked Segregant Analysis Using Dominant Markers. CROP SCl. 2000; 40(3):626-630.

20. Takagi H, Abe A, Yoshida K, Kosugi S, Natsume S, Mitsuoka C, et al. QTL-seq: rapid mapping of quantitative trait loci in rice by whole genome resequencing of DNA from two bulked populations. PLANT J. 2013; 74(1):174-183.

21. Trick M, Adamski NM, Mugford SG, Jiang CC, Febrer M, Uauy C. Combining SNP discovery from next-generation sequencing data with bulked segregant analysis (BSA) to fine-map genes in polyploid wheat. BMC Plant Biol. 2012; 12:14.

22. Wang R, Sun L, Bao L, Zhang J, Jiang Y, Yao J, et al. Bulk segregant RNA-seq reveals expression and positional candidate genes and allele-specific expression for disease resistance against enteric septicemia of catfish. BMC GENOMICS. 2013; 14:929.

23. Yuan YW, Sagawa JM, Di Stilio VS, Bradshaw HD. Bulk Segregant Analysis of an Induced Floral Mutant Identifies a MIXTA-like R2R3 MYB Controlling Nectar Guide Formation in Mimulus lewisii. GENETICS. 2013;194(2):523-528.

24. $\mathrm{Mu}$ J-H, Lee H-S, Kao T. Characterization of a pollen-expressed receptor-like kinase gene of Petunia inflata and the activity of its encoded kinase. Plant Cell. 1994; 6(5):709-721.

25. Jinn TL, Stone JM, Walker JC. HAESA, an Arabidopsis leucine-rich repeat receptor kinase, controls floral organ abscission. GENE DEV. 2000; 14(1):108-117.

26. Claisse G, Charrier B, Kreis M. The Arabidopsis thaliana GSK3/Shaggy like kinase AtSK3-2 modulates floral cell expansion. PLANT MOL BIOL. 2007; 64(1-2):113-124.

27. Jian H, Feng C, Cecilia DC, Antonella A, Mouhua S, Shuai Y, et al. An ankyrin repeat-containing protein, characterized as a ubiquitin ligase, is closely associated with membrane-enclosed organelles and required for pollen germination and pollen tube growth in lily. PLANT PHYSIOL. 2006; 140(4):1374-1383.

28. Niu BX, He FR, He M, Ren D, Chen LT, Liu YG. The ATP-binding Cassette Transporter OsABCG15 is Required for Anther Development and Pollen Fertility in Rice. J INTEGR PLANT BIOL. 2013; 55(8):710-720.

29. Schruff MC, Spielman M, Tiwari S, Adams S, Fenby N, Scott RJ. The AUXIN RESPONSE FACTOR 2 gene of Arabidopsis links auxin signalling, cell division, and the size of seeds and other organs. DEVELOPMENT. 2006, 133(2); 251-261.

30. Pandolfini T, Molesini B, Spena A. Molecular dissection of the role of auxin in fruit initiation. TRENDS PLANT SCI. 2007; 12(8):327-329.

31. De Jong M, Wolters-Arts M, Feron R, Mariani C, Vriezen WH. The Solanum lycopersicum auxin response factor 7 (SIARF7) regulates auxin signaling during tomato fruit set and development. PLANT J. 2009; 57(1):160-170.

Page $11 / 22$ 
32. Zhu Y, Nomura T, Xu Y, Zhang Y, Peng Y, Mao B, et al. ELONGATED UPPERMOST INTERNODE encodes a cytochrome P450 monooxygenase that epoxidizes gibberellins in a novel deactivation reaction in rice. PLANT CELL. 2006; 18(2):442-456.

33. Nafisi M, Goregaoker S, Botanga CJ, Glawischnig E, Olsen CE, Halkier BA, et al. Arabidopsis cytochrome P450 monooxygenase 71A13 catalyzes the conversion of indole-3-acetaldoxime in camalexin synthesis. PLANT CELL. 2007; 19(6):2039-2052.

34. Zhao Y, Christensen SK, Fankhauser C, Cashman JR, Cohen JD, Weigel D, et al. A Role for Flavin Monooxygenase-Like Enzymes in Auxin Biosynthesis. Science. 2001; 291(5502):306-309.

35. Ito T, Meyerowitz EM. Overexpression of a Gene Encoding a Cytochrome P450, CYP78A9, Induces Large and Seedless Fruit in Arabidopsis. PLANT CELL. 2000; 12(9):1541.

36. Meyer S, Scholz-Starke J, De Angeli A, Kovermann P, Burla B, Gambale F, et al. Malate transport by the vacuolar AtALMT6 channel in guard cells is subject to multiple regulation. PLANT J. 2011; 67(2):247-257.

37. Yang B, Dougherty L, Li M, Fazio G, Cheng L. A natural mutation-led truncation in one of the two aluminum-activated malate transporter-like genes at the locus is associated with low fruit acidity in apple. MOL GENET GENOMIC. 2012; 287(8):663-678.

38. Bolger AM, Lohse M, Usadel B. Trimmomatic: a flexible trimmer for Illumina sequence data. Bioinformatics (Oxford, England) 2014; 30(15):2114-2120.

39. Jaillon O, Aury J, Noel B, Policriti A, Clepet C, Casagrande A, et al. The grapevine genome sequence suggests ancestral hexaploidization in major angiosperm phyla. Nature. 2007; 449(7161):463 - 467.

40. Li H, Durbin R. Fast and accurate short read alignment with Burrows-Wheeler transform. Bioinformatics (Oxford, England) 2009; 25(14):1754-1760.

41. Li H, Handsaker B, Wysoker A, Fennell T, Ruan J, Homer N, et al. The Sequence Alignment/Map format and SAMtools. Bioinformatics (Oxford, England) 2009; 25(16):2078-2079.

42. Joung JG, Corbett AM, Fellman SM, Tieman DM, Klee HJ, Giovannoni JJ, et al. Plant MetGenMAP: an integrative analysis system for plant systems biology. Plant Physiol. 2009; 151(4):1758-1768.

43. Hill JT, Demarest BL, Bisgrove BW, Gorsi B, Su Y-C, Yost HJ. MMAPPR: mutation mapping analysis pipeline for pooled RNA-seq. GENOME RES. 2013; 23(4):687-697.

44. Guo C, Guo R, Xu X, Gao M, Li X, Song J, et al. Evolution and expression analysis of the grape (Vitis vinifera L.) WRKY gene family. J Exp Bot. 2014; 65(6):1513-1528.

\section{Tables}

Table 1. Information of high quality clean reads mapped with reference genome

\begin{tabular}{cccccc}
\hline Sample & All Reads & Single Mapped Reads & Paired Mapped Reads & Unmapped Reads & Align Ratio(\%) \\
\hline C & 57160754 & 136895 & 27239591 & 2544677 & 95.55 \\
R & 68761692 & 179104 & 32691359 & 3199870 & 95.35 \\
SL & 50978504 & 192890 & 24333081 & 2119452 & 95.84 \\
S & 56263426 & 224997 & 26903173 & 2232083 & 96.03 \\
\hline
\end{tabular}

Table 2. Function classification of genes containing functional variants 


\begin{tabular}{|c|c|c|c|}
\hline Function classification & Associated genes & $\begin{array}{l}\text { Associated DEGs } \\
\text { at least at one stage }\end{array}$ & $\begin{array}{l}\text { Associated DEGs } \\
\text { at all three stages }\end{array}$ \\
\hline frameshift deletion & 454 & 124 & 35 \\
\hline frameshift insertion & 309 & 91 & 24 \\
\hline nonsynonymous SNP & 11381 & 3790 & 1147 \\
\hline \multirow[t]{2}{*}{ stopgain } & 10 & 3 & 1 \\
\hline & 13 & 3 & 1 \\
\hline SNP & 298 & 68 & 14 \\
\hline \multirow[t]{2}{*}{ stopless } & 6 & 2 & 1 \\
\hline & 15 & 6 & 3 \\
\hline SNP & 214 & 52 & 15 \\
\hline
\end{tabular}

Table 3. Identified candidate genes based on expression analysis from transcriptome

\begin{tabular}{|c|c|c|c|c|c|c|c|c|c|}
\hline \multirow[t]{2}{*}{ Gene ID } & \multirow{2}{*}{$\begin{array}{l}\text { Gene } \\
\text { name }\end{array}$} & \multirow[t]{2}{*}{ Chr } & \multirow[t]{2}{*}{ Position } & \multirow[t]{2}{*}{ Ref } & \multirow[t]{2}{*}{ Mut } & \multirow[t]{2}{*}{ Description } & \multicolumn{3}{|c|}{ Ratio(Seedless/Seeded) } \\
\hline & & & & & & & $\begin{array}{c}\text { Stage } \\
1 \\
\end{array}$ & $\begin{array}{c}\text { Stage } \\
2 \\
\end{array}$ & $\begin{array}{c}\text { Stage } \\
3\end{array}$ \\
\hline GSVIVG01036048001 & G1 & chr6 & 21418457 & $\mathrm{C}$ & G & $\begin{array}{l}\text { Phosphatidylglycerol/phosphatidylinositol } \\
\text { transfer protein }\end{array}$ & 1 & 2.19 & 0.89 \\
\hline GSVIVG01011008001 & G2 & chr7 & 2257286 & G & A & Putative auxin response factor 2 & 0.2 & 0.08 & 0.56 \\
\hline GSVIVG01011007001 & G3 & chr7 & $\begin{array}{l}2266373 \\
2266664\end{array}$ & $\begin{array}{l}\mathrm{C} \\
\mathrm{C}\end{array}$ & $\begin{array}{l}\mathrm{T} \\
\mathrm{T}\end{array}$ & Serine & 2.37 & 1.48 & 6 \\
\hline GSVIVG01011006001 & G4 & chr7 & 2278664 & A & $\mathrm{C}$ & Monooxygenase, putative & 5.99 & 3.15 & 6.07 \\
\hline GSVIVG01000977001 & G5 & chr13 & 11040377 & A & $\mathrm{T}$ & $\begin{array}{l}\text { Histidine kinase-like ATPase domain- } \\
\text { containing protein }\end{array}$ & 2.75 & 0.12 & 0.83 \\
\hline GSVIVG01000993001 & G6 & chr13 & $\begin{array}{l}11222492 \\
11223120 \\
11223228 \\
11223476\end{array}$ & $\begin{array}{l}\mathrm{G} \\
\mathrm{T} \\
\mathrm{C} \\
\mathrm{C}\end{array}$ & $\begin{array}{l}\text { A } \\
\text { C } \\
\text { A } \\
\text { T }\end{array}$ & Tir-nbs-Irr resistance protein & 188 & 3.51 & 33.3 \\
\hline GSVIVG01000994001 & G7 & chr13 & 11229443 & G & A & Aluminum-activated malate transporter & 27.97 & 2.56 & 6.88 \\
\hline GSVIVG01000995001 & G8 & chr13 & 11240814 & G & A & $\begin{array}{l}\text { Putative aluminum-activated malate } \\
\text { transporter }\end{array}$ & 10.62 & 2.88 & 5.59 \\
\hline GSVIVG01001005001 & G9 & chr13 & $\begin{array}{l}11336347 \\
11337398\end{array}$ & $\begin{array}{l}\mathrm{T} \\
\mathrm{G}\end{array}$ & $\begin{array}{l}\mathrm{C} \\
\mathrm{C}\end{array}$ & Protein trichome birefringence-like 36 & 5.83 & 6.6 & 4.09 \\
\hline
\end{tabular}

\section{Additional Files}

Additional file 1: Figure S1. Base composition and quality value distribution after data filtering. Line A, T, C and G indicate the percent of corresponding base at each position, respectively. Mean refers to the average quality of all bases at each position, while Q20 and Q30 indicate the percent of bases with quality value no less than 20 and 30, respectively.

Additional file 2: Table S1. Base information before and after filtering. 'C' represents 'Centennial seedless', 'R' 'Red Globe', 'S' 'Seeded progeny', and 'SL' 'seedless progeny'. 
Additional file 3: Table S2. Reads information before and after filtering. 'C' represents 'Centennial seedless', 'R' 'Red Globe', 'S' 'Seeded progeny', and 'SL' 'seedless progeny'.

Additional file 4: Table S3. Number of DEGs containing functional variants.

Additional file 5: Figure S2. Distribution of SNP-index. The x-axis indicates the chromosomal position, each spot represents a SNP. Average values of SNP-index or delta SNP were indicated by the black lines. (a). SNP-index plot of 'Seeded' bulk; (b). SNP-index plot of 'Seedless' bulk; (c). Plot of delta SNP-index. The red line indicate the threshold line.

Additional file 6: Table S4. Functional variants in the valley.

Additional file 7: Table S5. Functional variants in the peak.

Additional file $8 \square$ Figure S3. Distribution of candidate genes based on expression analysis from transcriptome data.

Additional file 9: Table. S6. The primer sequences used for expression analysis.

\section{Figures}




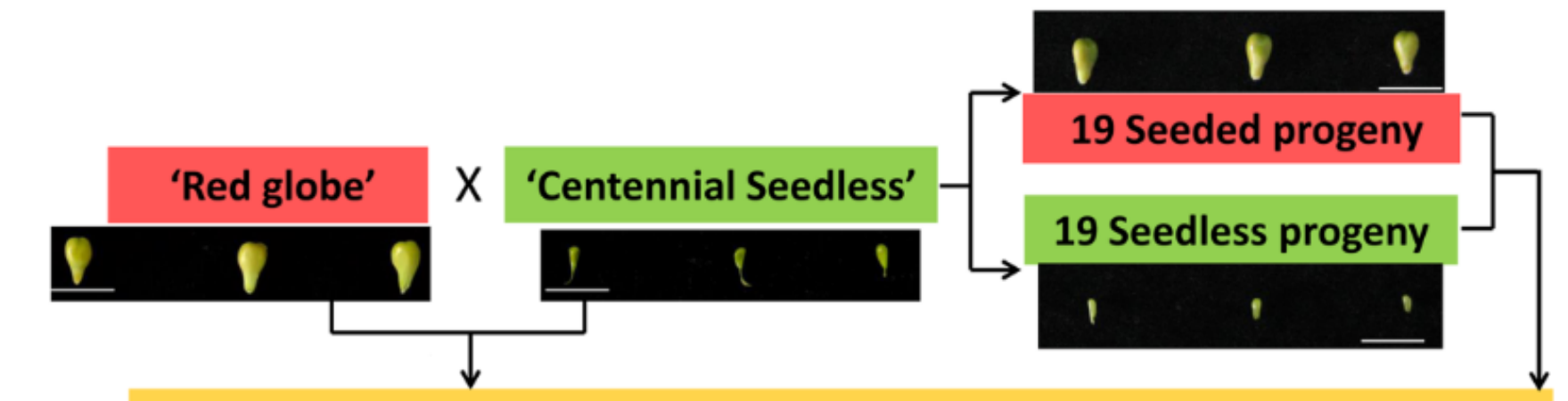

Leaf collection, sample mix of seeded and seedless progeny, respectively

$\downarrow$

Genome sequencing and identification of genomic variants

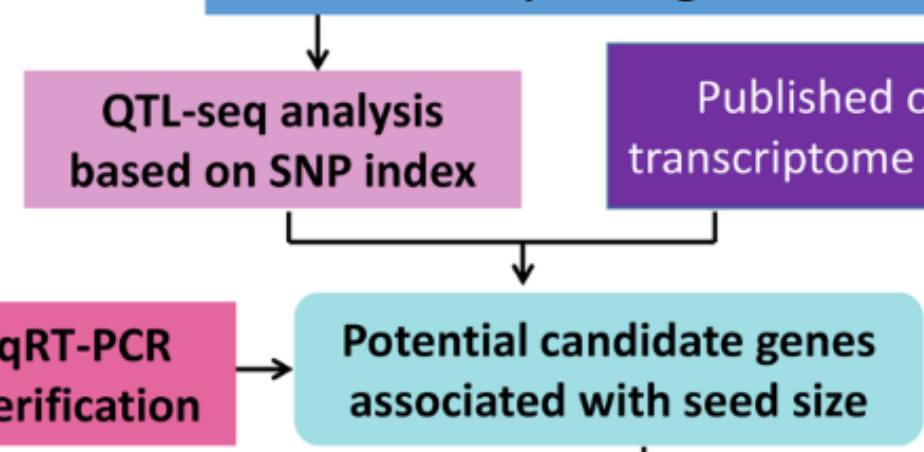

$\downarrow$

QTL-seq analysis based on SNP index

transcriptome analysis

Functional variants

verification

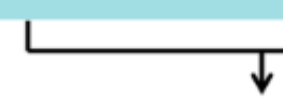

Identification and analysis of DEGs containing functional variants,

Conjectures of grape seed size associated functional variants and potential mechanism

Figure 1

Overview of the experimental design used in this study. Scale bars are $1 \mathrm{~cm}$. 
a

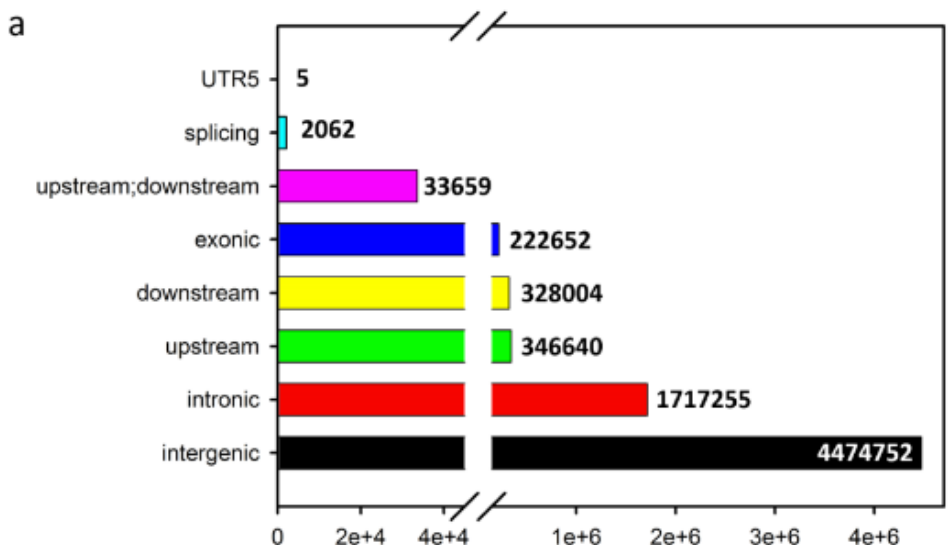

b

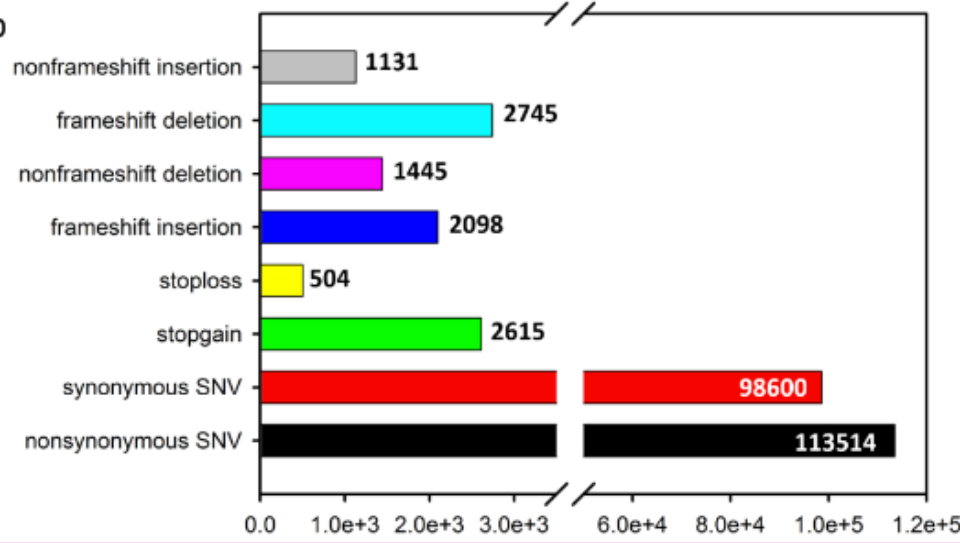

C

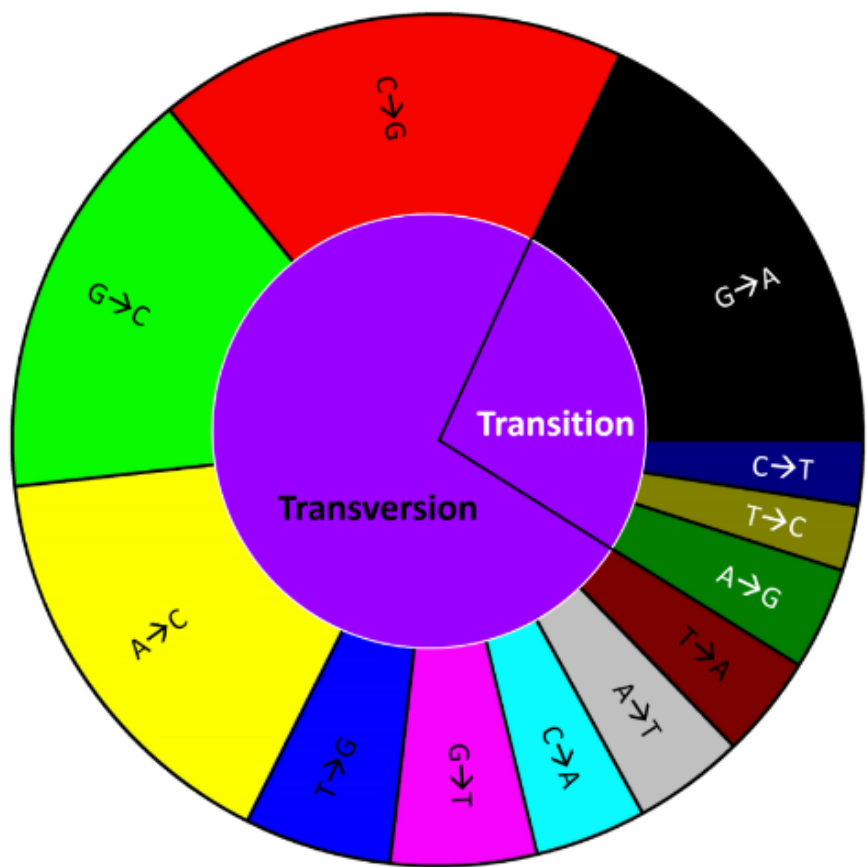

Figure 2

Information about identified genomic variants. (a). Position of variants in relation to genes. (b). Functional consequences of variants within exons. (c). Transitions and transversions analysis of genomic SNP

a

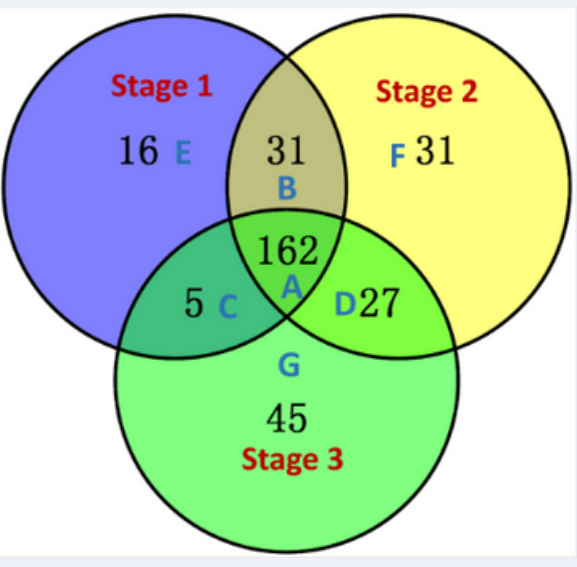

b

A defense response; reproductive process gametophyte/stamen/inflorescence /embryo sacdevelopment hormone-mediated signaling; programmed cell death response to salicylic acid/abscisic acid/ethylene stimulus mucilage metabolic process during seed coat development cellulose biosynthetic/metabolic process Endosperm/seed coat/seed development killing of cells of another organism

killing of cells of another organism lignin biosynthetic process; secondary $\mathrm{m}$
oxidation reduction; iron ion transport

B Pollen/Inflorescence/ flower/embryonic development polarity specification of adaxial/abaxial axis cell wall catabolic process ; anatomical structure formation lignin metabolic process

C Cytokinin/hormone catabolic process amino acid derivative metabolic/ biosynthetic process

D amino acid and derivative metabolic process oxidation reduction; cell killing; Ripening positive regulation of flower development flavonoid biosynthetic process

detection of hormone stimulus; brassinosteroid homeostasis di-, tri-valent inorganic cation transport response to auxin stimulus

embryonic development ending in seed dormancy lateral root development; tissue development cell wall organization/loosening secondary cell wall biogenesis positive regulation of cell growth/cell size

F cell wall modification response to gibberellin stimulus multicellular organism reproduction regulation of flower development Meristem/flower development Mitosis; cell cycle process reproductive structure development

G hormone metabolic process positive regulation of developmental process ethylene metabolic/biosynthetic process lignin metabolic process lipid biosynthetic/metabolic process cellular cation homeostasis

\section{Figure 3}

Analysis of GO terms associated with DEGs containing functional variants. (a). Venn analysis of GO terms at three developmental stages. (b). Enrichment of identified GO terms. The red and green color indicate enriched GO terms associated with up- and down-regulated DEGs, respectively 
a

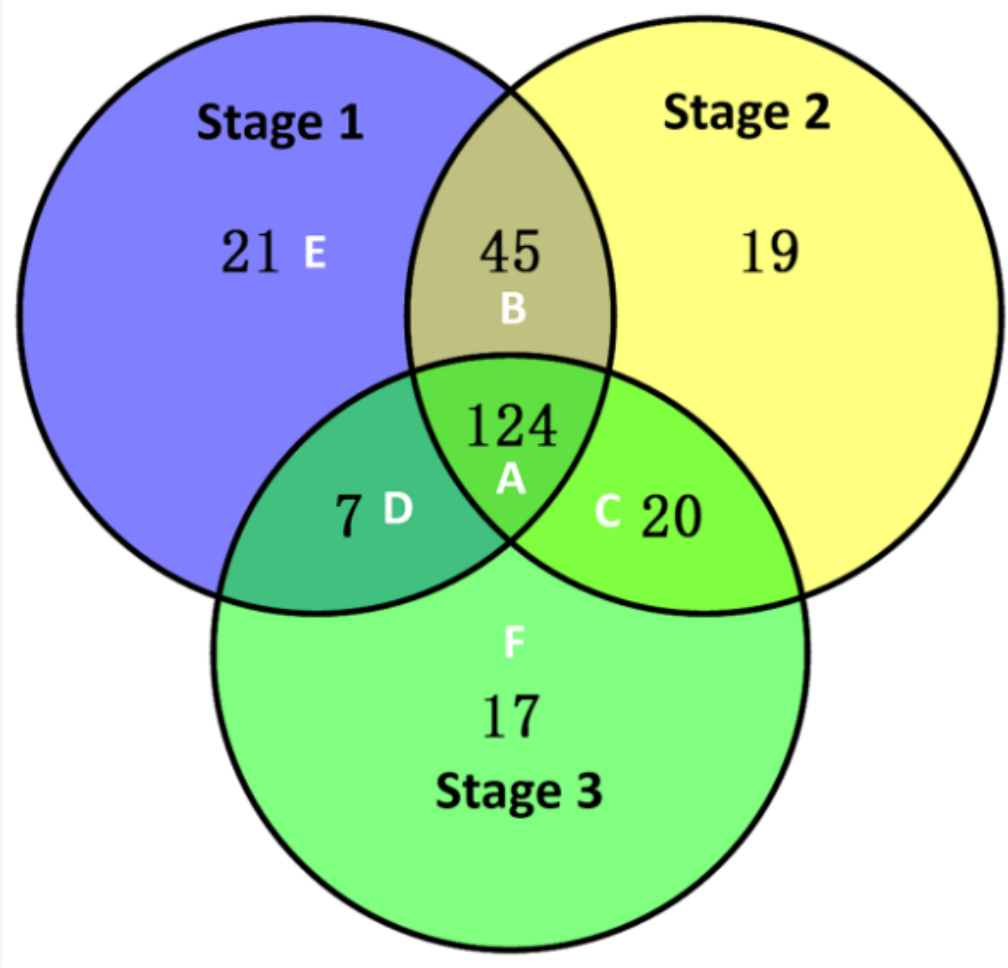

b

A cytokinins degradation cis-zeatin biosynthesis jasmonic acid biosynthesis ethylene biosynthesis from methionine cellulose biosynthesis suberin biosynthesis flavonoid biosynthesis glutathione-mediated detoxification

B sucrose biosynthesis abscisic acid biosynthesis

C fatty acid biosynthesis trans-zeatin biosynthesis GA12 biosynthesis

D IAA biosynthesis

E GA12 biosynthesis

F gibberellin inactivation

Figure 4

Pathways enrichment of DEGs containing functional variants. (a). Venn analysis of pathways at three developmental stages.

(b). Enrichment of identified pathways 


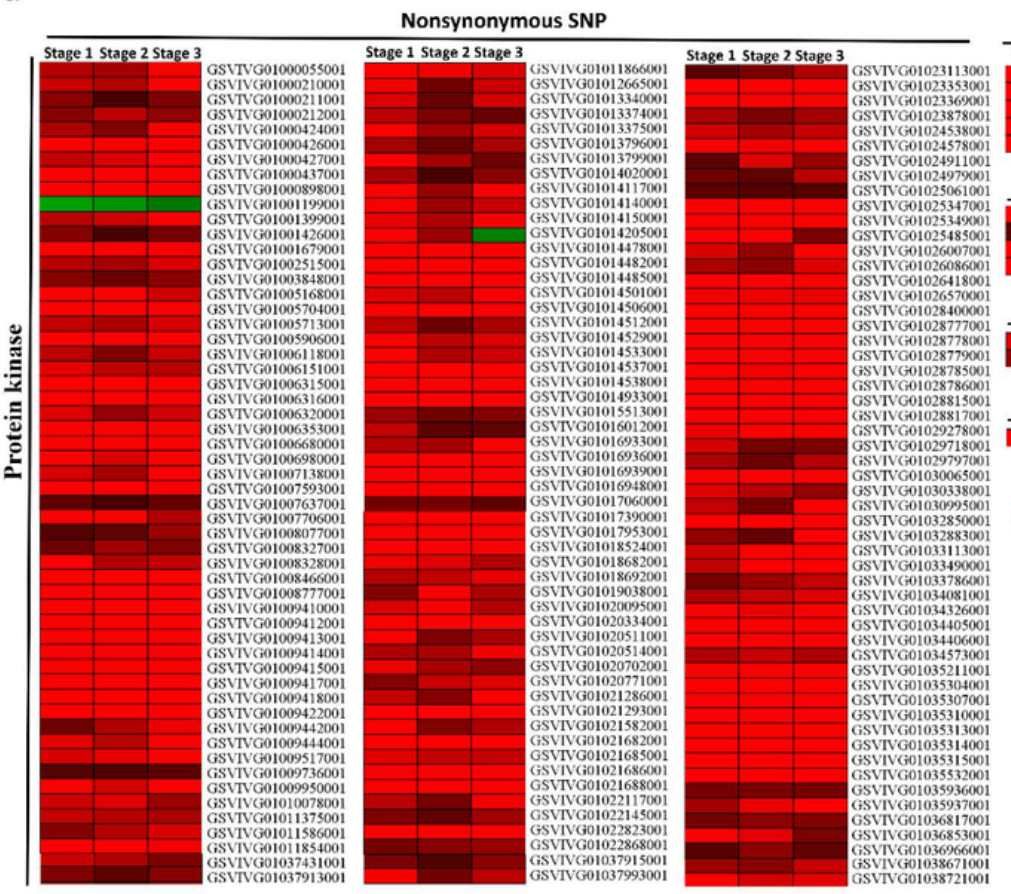

Frameshift deletion

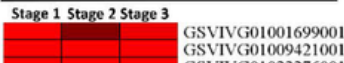
GSVIVG01023376001 GSVIVGO1023382001
GSVIVGol027831001

Frameshift insertion

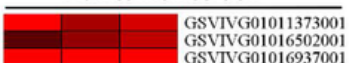
SVVIVG01016937001

Stopgain SNP

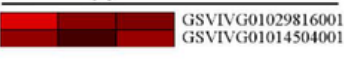

Stopless SNP

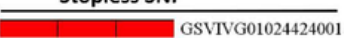

b

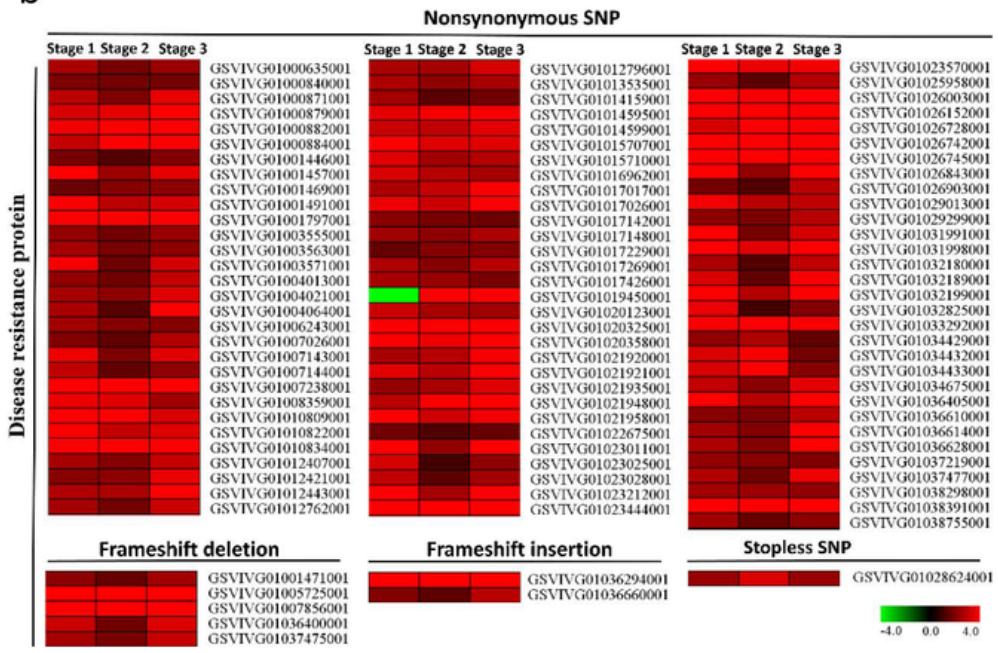

C
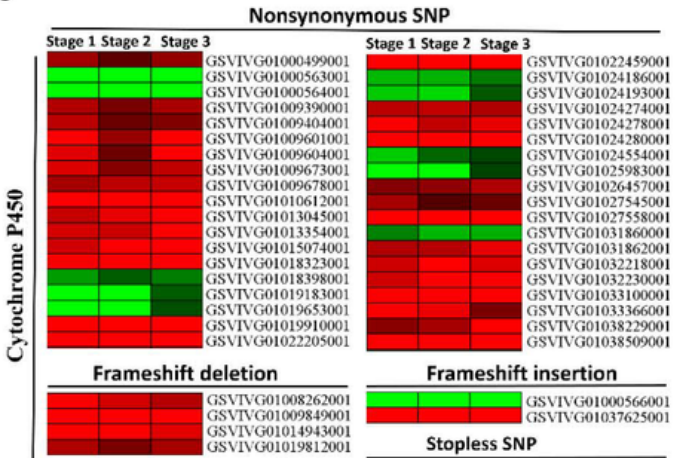

Frameshift insertion

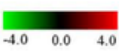

Stop

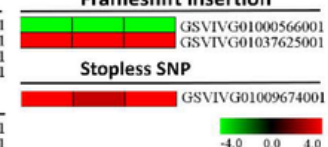

\section{Figure 5}

Expression profile of DEGs containing functional variants at three developmental stages. (a). Expression profile of DEGs encoding protein kinases. (b). Expression profile of DEGs encoding disease resistant proteins. (c). Expression profile of DEGs encoding cytochrome P450s. 


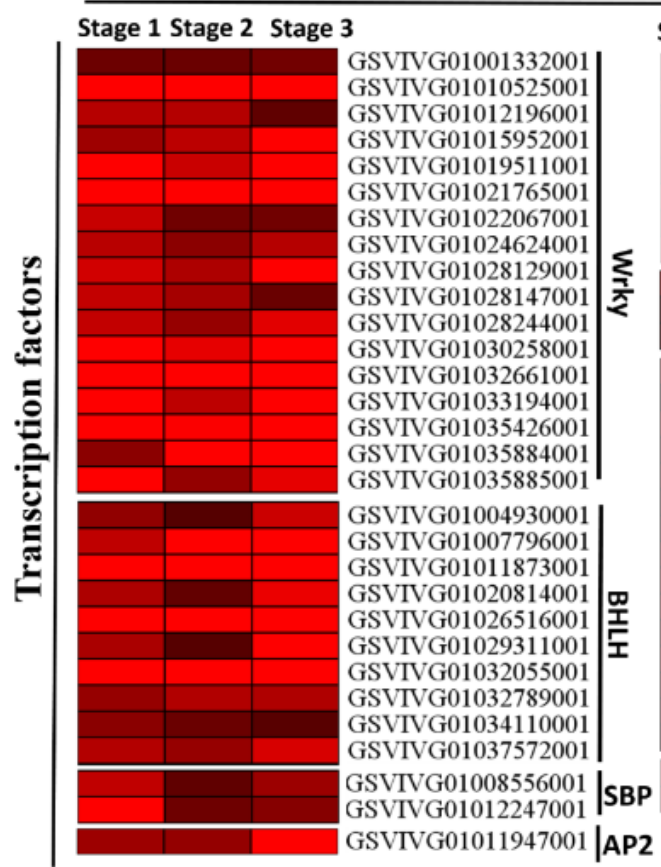

Frameshift deletion

\section{Stage 1 Stage 2 Stage 3}
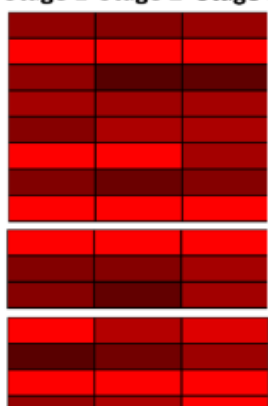

GSVIVG01003431001 GSVIVG01007715001 GSVIVG01013388001 GSVIVG01018947001 GSVIVG01020033001 GSVIVG01021144001 GSVIVG01032491001 GSVIVG01038619001 GSVTVG01020011001 GSVIVG01021528001 GSVIVG01023283001 GSVIVG01001089001 GSVIVG01004798001 GSVIVG01013905001 GSVIVG01013914001 GSVTVG01013916001 GSVIVG01013917001 GSVIVG01013931001 GSVTVG01013934001 ERF GSVIVG01015037001 GSVIVG01015037001 GSVIVG01019860001 GSVIVG01021146001 GSVIVG01028315001 GSVIVG01035098001 GSVIVG01035098001
GSVIVG01035852001 \begin{tabular}{l|l} 
GSVIVG01015389001 \\
GSVIVG01033781001
\end{tabular}

Stage 1 Stage 2 Stage 3

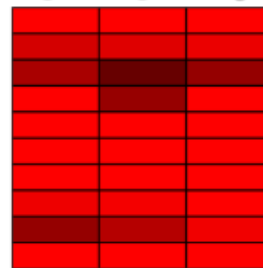

GSVIVG0100367500 GSVIVG01004464001 GSVIVG01016996001 GSVIVG01020827001 GSVIVG01021225001 GSVTVG01027810001 GSVIVG01027811001 GSVIVG0103379200 GSVTVG01035332001 GSVIVG01035459001

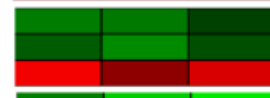

GSVIVG01000802001 GSVIVG0100143700 GSVIVG GSVIVG01033067001 GSVTVG01013182001 GSVIVG01022354001 GSVTVG01027475001 GSVIVG01033032001 NAC GSVIVG0103521400 GSVIVG01038666001 GSVIVG01024194001 |GATA GSVIVG01014246001 GSVIVG01022363001 |Bzip GSVIVG01022363001 GSVIVG01016790001 |CCAAT GSVIVG01004104001

GSVIVG01004104001 |GRAS

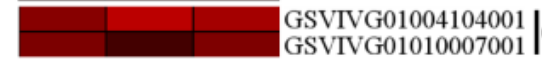
GSVIVG01032785001 ERF

Stopgain SNP

GSVIVG01016767001 Myb
Stopless SNP

Figure 6

Expression profile of functional variant-DEGs encoding transcription factors at three developmental stages. 


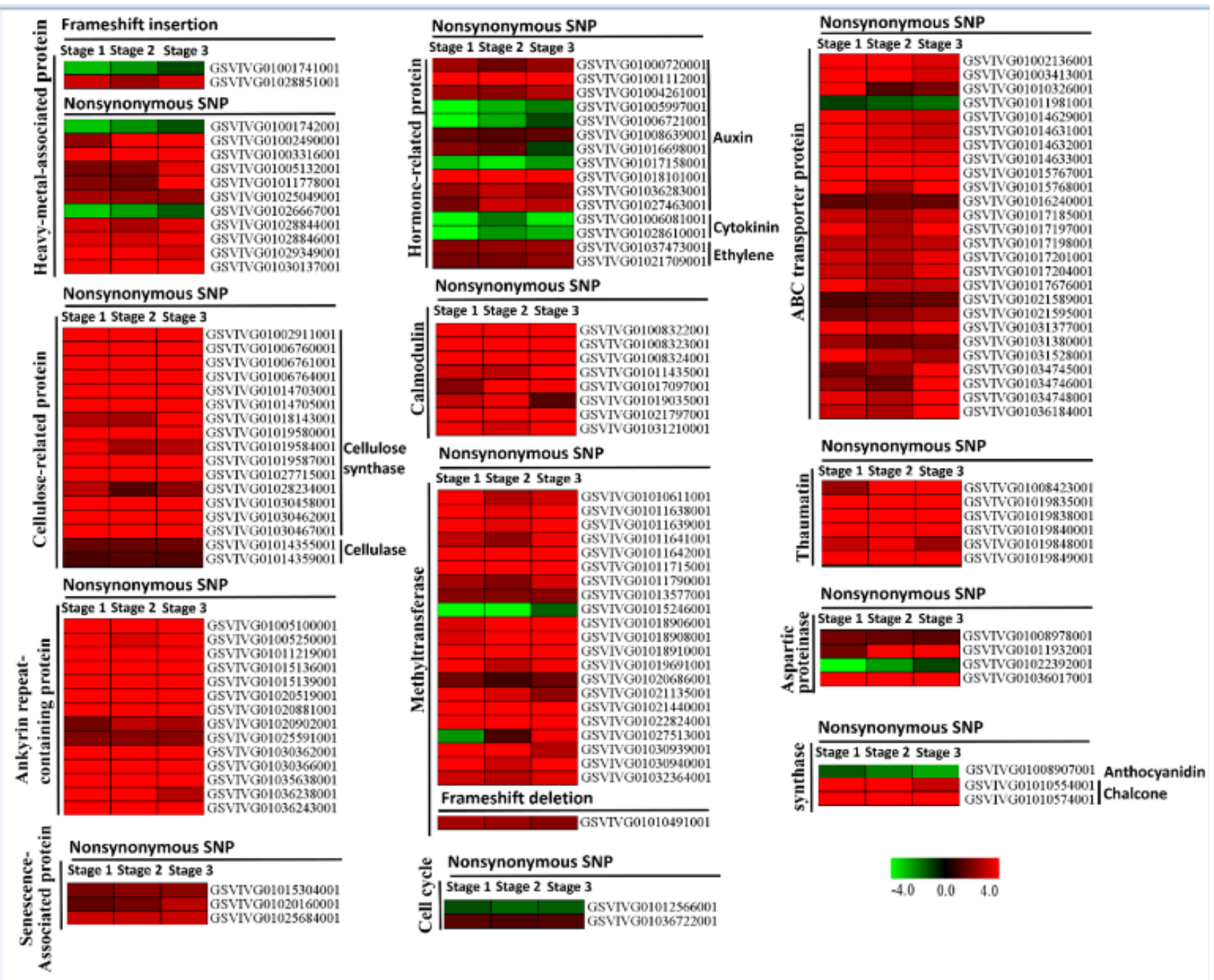

Figure 7

Expression profile of functional variant DEGs affecting seed development at three developmental stages. 


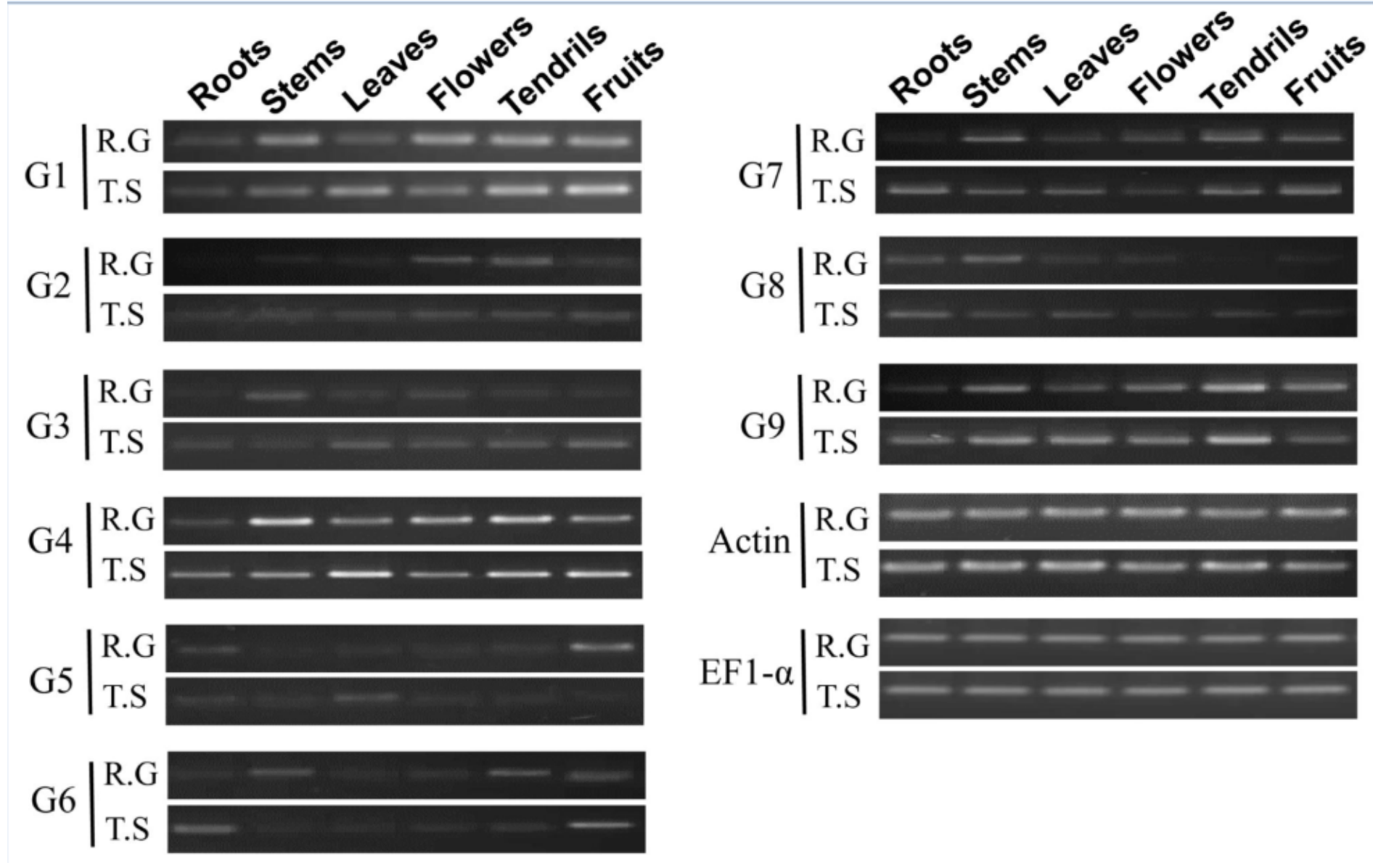

Figure 8

Tissue-specific expression profiles of candidate genes containing functional variants. 'R.G' stands for 'Red Globe' and 'T.S' 'Thompson Seedless'. 

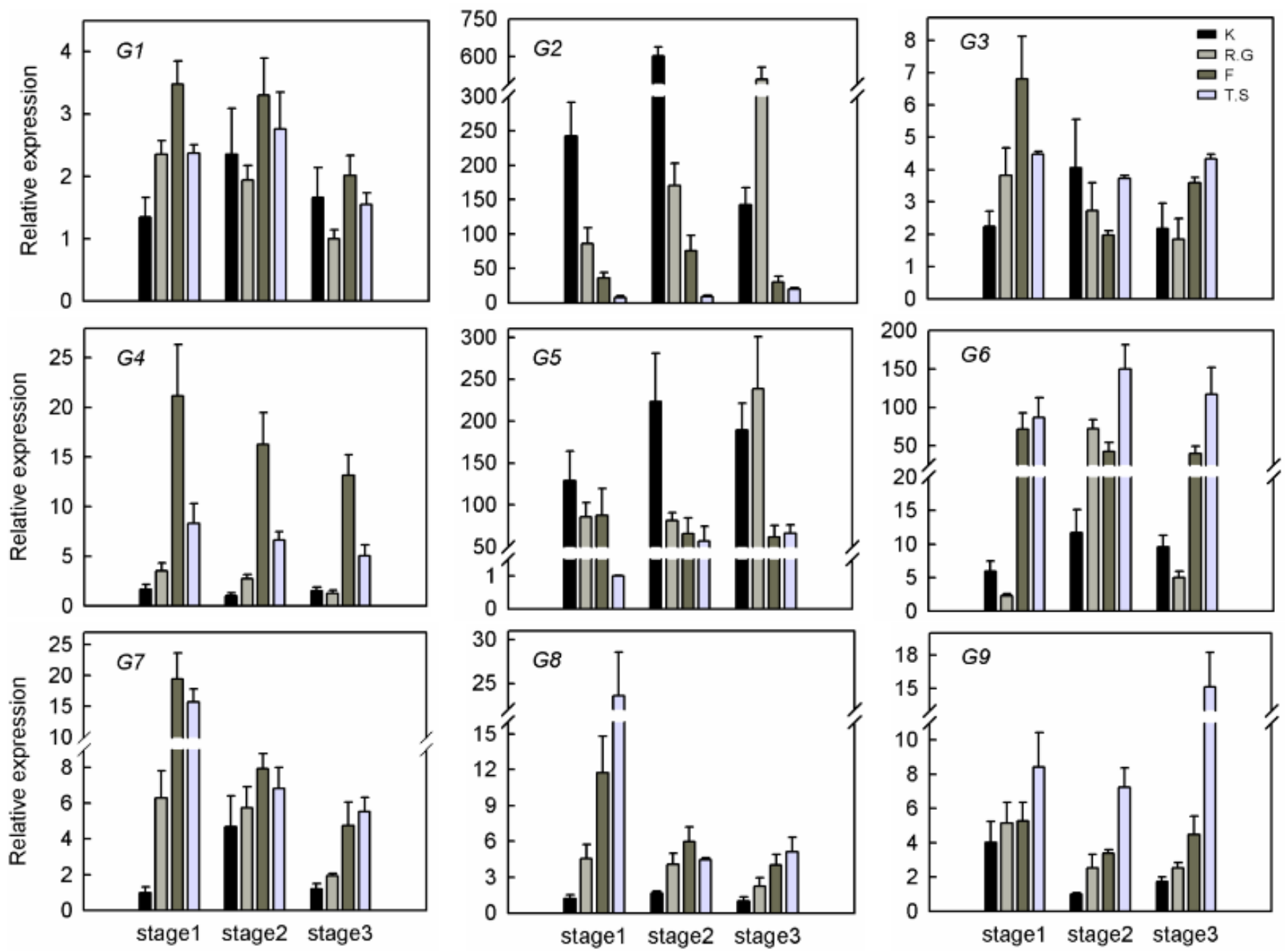

Figure 9

Real-time quantitative PCR expression levels of candidate genes containing functional variants during ovule development of seeded and seedless cultivars. Mean values and SDs were obtained from three biological and three technical replicates. ' $\mathrm{K}$ ' stands for 'Kyoho', 'R.G' 'Red Globe', 'F' 'Flame Seedless' and 'T.S' 'Thompson Seedless'.

\section{Supplementary Files}

This is a list of supplementary files associated with this preprint. Click to download.

- Supplementalfiles.rar 